Kristina Tomc

\title{
Phoebus volentem proelia me loqui: Kalimahov Apolon pri Horaciju
}

\section{UVOD: OD KALIMAHA DO AVGUSTEJSKIH PESNIKOV}

Kalimah v svojem Prologu k pesnitvi Ajtia pripoveduje, kako ga je v rosnih letih, ko se je prvič lotil pisanja, nagovoril bog pesništva:

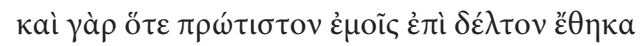

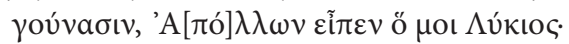

‘...........̉oıı

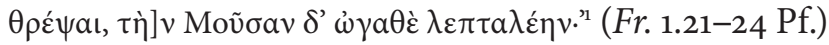

Že ko sem prvič deščíco voščeno položil h kolenom, rekel je lidijski bog Fojbos Apolon tako:

»Kadar daruješ mi, dobri in dragi prijatelj, kadila mera naj težka ti bo, Muza pa lahka, poet! «²

Ti verzi so naleteli na številne odmeve pri pesnikih avgustejske dobe, saj najdemo paralelna mesta pri Vergiliju, Horaciju, Properciju in Ovidiju. ${ }^{3}$ Zasluge za to je treba v veliki meri pripisati Vergilijevi šesti eklogi, ki postane zgled za pesnikovo 'opravičevanje', za t. i. recusatio. ${ }^{4}$ Verzi $3-5$ se glasijo takole:

cum canerem reges et proelia, Cynthius aurem

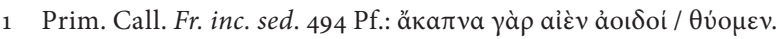

2 Prev. Kajetan Gantar.

3 Verg. Ecl. 6.3-5; Prop. 2.13.3; 3.3.13; 3.3.39; 4.1.73; 4.1.133; Ov. Am. 1.1.1; 2.18.13; Ars am. 2.493-508. Prim. Wimmel, Kallimachos in Rom, 135-41.

4 Več o recusatio v: White, Promised Verse, 64-91, in Lyne, Horace, 31-39. 
uellit et admonuit: "pastorem, Tityre, pinguis

pascere oportet ouis, deductum dicere carmen.«

Pel sem o kraljih in bojih, a glej, za uho me povleče

Kintijec ter mi zabiča: »Pastirju je, Titir, to vedi,

vzrejati tolste ovcé, a peti pretanjeno pesem. " $^{5}$

Poudarek se prenese s stila na razmerje med zvrstmi, med 'veliko' epiko in 'manjšo' bukolično poezijo. Verzi tako dobijo tudi politično ostrino, ki je pri Kalimahu ni bilo. ${ }^{6}$

Pri Horaciju vlogo Apolona, ki pesnika opozarja, kako naj piše, štirikrat prevzame nekdo drug: v Epod. 14.6-8 deus (verjetno gre za Kupida), ${ }^{7}$ v C. 1.6.10-12 Muza, v C. 1.19.9-12 Venera in v S. 1.10.31-35 Kvirin. ${ }^{8}$ V Satiri 2.6.1415 lahko navodilo Kalimahovega Apolona razberemo iz Horacijeve prošnje Merkurju, enkrat samkrat, v zadnji odi (C. 4.15.1-4), pa svarilo pride iz Apolonovih ust.

\section{ODA 1.6, ODA 1.19 IN EPODA 14: MUZA, VENERA IN DEUS V VLOGI KALIMAHOVEGA APOLONA}

V treh izmed navedenih primerov gre le za podobno situacijo kot pri Kalimahu, za prikaz božanstva, ki naj bi pesniku preprečilo, da bi napisal, kar si je zamislil oziroma kar od njega pričakujejo drugi. Horacij ne navaja besed 'višje sile', ki naj bi posegla v njegov ustvarjalni proces, ampak le na kratko poroča o njih, da bi bilo njegovo 'opravičilo' bolj učinkovito.

$\mathrm{V}$ šesti odi prve knjige gre za tako rekoč tipično recusatio: Horacij zavrne pisanje epa z mitološko oziroma zgodovinsko vsebino, saj pudor (9) in mogočna Muza imbellis lyrae (10) prepovedujeta »laudes egregii Caesaris et tuas (sc. Agrippae) / culpa deterere ingeni« (11-12), zato raje opeva gostije in ljubezenske boje. Tudi Venera, ki v devetnajsti pesmi plane (»in me tota ruens«, 9) na zaljubljenega Horacija, ne dovoli pisanja o resni tematiki (»Scythas / et uersis animosum equis / Parthum «, 10-12). ${ }^{9}$

$\mathrm{V}$ štirinajsti epodi Horacij Mecenatu pojasni, da mu bog prepoveduje dokončati obljubljene in že začete jambe. ${ }^{10}$ Tudi tokrat naj bi prevladala lahkotnejša ljubezenska poezija $\mathrm{v}$ anakreontski maniri, zato so se mnogi spraševa-

5 Prim. Kambylis, Die Dichterweihe und ihre Symbolik, 141; Lyne, Horace, 32-33; Brink, Horace on Poetry, 532, op. 5.

6 Prim. Watson, Commentary on Horace's Epodes, ad loc.

7 Do podobnega premika pride tudi pri Properciju (2.13.3: Amor; 3.3.39: Kaliopa; 4.1: Horus) in pri Ovidiju (Am. 1.1.1 in 2.18.13: Amor).

8 Prim. Lefèvre, Horaz, 196-97.

9 Watson, »Epode 14", 188-89, navaja primere podobnih 'prelomljenih obljub'.

10 Kiessling, Heinze, Quintus Horatius Flaccus, ad loc.; Wili, Horaz und die augusteische Kultur, 61-62; Ingallina, "Non elaboratum ad pedem«, 202. 
li, ali gre v tej epodi sploh še za jambe ali že za liriko, številni pa so v Horacijevih verzih prepoznali napoved spremembe in obrat k ljubezenskim Odam. ${ }^{11}$ Kot v C. 1.6 recusatio omogoči, da v liriko vstopi druga zvrst, epika, tako se zdaj prepleteta jambska in lirska poezija. ${ }^{12}$ Vendar je situacija v štirinajsti epodi bolj zagonetna, saj Horacij epa vendarle ne napiše, čeprav iz C. 1.6 lahko sklepamo, da bi to zmogel. V obravnavani epodi gre za tehnično izpiljeno jambsko poezijo, ki govori o Horacijevi nezmožnosti, da bi pisal jambe. ${ }^{13}$ Verzi nosijo močan pečat kalimahejske in neoterične poetike, poiščemo pa lahko tudi vzporednice k Lukreciju, Vergiliju in Anakreontu oziroma anakreontiki. S tega vidika so zelo zanimivi ravno verzi o bogu, ki Horaciju veleva, naj ne zaključi svojih jambov:

deus, deus nam me vetat

inceptos olim, promissum carmen, iambos

ad umbilicum adducere. (6-8)

bog, bog mi namreč prepoveduje, da bi jambe, ki sem jih že davno začel, obljubljeno pesem, pripeljal do konca.

Podvojeni deus, ki ustvarja lažno občutje privzdignjenega sloga, spominja na Vergilijevo peto eklogo (64), na Lukrecijevo pesnitev (5.8) in na številna mesta v zbirki Anacreontea. ${ }^{14}$ Vrstni red v drugem verzu po Watsonovem mnenju nedvomno sodi v neoterično tradicijo. ${ }^{15}$ Nenavadno je, da Horacij ne razkrije imena boga, ki igra tako pomembno vlogo. Šele iz nadaljevanja lahko sklepamo, da gre za Kupida, a povezava tudi zdaj ni eksplicitna. Horacij svoje stanje primerja z Anakreontovo zaljubljenostjo v Batila, ki je povzročila, da je pesnik "persaepe caua testudine fleuit amorem / non elaboratum ad pedem « (11-12). Če je torej grškemu poetu vladal Amor, mora biti prav Amor deus iz šestega verza. Watson opozarja, da tako posredno izvemo tudi za zvrst, ki jo bog odobrava. ${ }^{16}$ Horacij torej v kalimahejski maniri zavrne tipično kalimahejsko $\mathrm{zvrst}^{17}$ in dá prednost drugi, ljubezenski liriki. ${ }^{18}$

11 Harrison, "Some Generic Problems in Horace's Epodes«, 182-83; isti, »Literary Form of Horace's Odes«, 137-41; Davis, Polyhymnia, 33-39; Nisbet, Hubbard, Commentary on Horace, ad C. 1.6.

12 Watson, „Epode 14", 189. Prav tam, 190, Watson poudarja, da v štirinajsti epodi ne gre za recusatio, ampak le za humorno izposojo nekaterih njenih značilnosti. Prim. C. 4.2, ki obravnava neposnemljivega Pindarja, obenem pa tako slogovno kot vsebinsko aludira na njegovo poezijo.

$131.6-7 ; 9.2-3,9,19 ; 12.12 ; 13.1 ; 15.2 ; 53.3$ West. Watson, Commentary on Horace, 440-41, predvideva, da je na Horacija vplival tudi Anakreon sam.

14 Watson, "Epode 14", 191; morda je paralelno mesto tudi pri Arhilohu, fr. 196a 49-50 W.

15 Watson, "Epode 14«, 196.

16 O Kalimahovem vplivu na Horacijeve Epode prim. Cavarzere, Orazio, 21-26, in Watson, Commentary on Horace, pass.

17 Do podobnega zaključka pride tudi Watson, „Epode 14", 200-3, vendar se paradoksu poskusi izogniti s tem, da zavrnjeno jambsko poezijo omeji na »ambiciozne politične Epode«, kot sta prva in deveta, pod preferirano liriko pa razume »extemporised sympotica «v Anakreontovem duhu.

18 Prev. Kajetan Gantar. 


\section{SATIRA 1.10: KVIRIN MI TO JE ZABRANIL}

Podobno paradoksalna kot $\mathrm{v}$ štirinajsti epodi je relacija do Kalimaha v programski Satiri 1.10. Navezava na Apolona iz Prologa k pesnitvi Ajtia je tu še dosti očitnejša:

atque ego cum Graecos facerem, natus mare citra, versiculos, vetuit me tali voce Quirinus

post mediam noctem visus, cum somnia vera:

»in silvam non ligna feras insanius ac si

magnas Graecorum malis inplere catervas.« (31-35)

Toda tedaj, ko jaz, ki tostran morja sem rojen, grške sem verze koval, Kvirin mi to je zabranil, že po polnóči se sam je prikazal, ko sen je resničen:

»Kaj to neumnost počneš? Rajši v hosto prenašaj polena, kot da poskušaš povečati grških poetov krdela! «19

Kvirin, izrazito rimski bog, deificirani Romul, v sanjah ${ }^{20}$ opozori mladega pesnika, da je pisanje grških verzov popolnoma nesmiselno. Rimskost je poudarjena tudi kasneje, ko namesto Muz srečamo Kamene (45). ${ }^{21}$ Kalimahova téma tokrat znova zaživi v povsem novi različici. Ne gre za poročilo o dejanskem srečanju z bogom, ampak za sanje. Pri Kalimahu v spanju poteka le pogovor z Muzami, Apolonovo opominjanje pa naj bi bilo realno doživetje budnega mladeniča. Tudi pri Vergiliju sanje niso povod za Apolonov nastop. Na Horacijeve verze je verjetno vplival opis Enijevih sanj, v katerih Enij sam nastopi kot reinkarnacija Homerja. Kvirin in njegove besede niso pomembni le zaradi domovinske note, ki jo vnašajo $\mathrm{v}$ satiro, ampak so tesno vgrajeni $\mathrm{v}$ vsebino te zapletene pesmi.

Satira 1.10 je tematsko nadaljevanje četrte satire, v kateri Horacij ostro kritizira svojega predhodnika, pesnika Lucilija. Pri tem se sklicuje na značilne ideale kalimahejske poetike in uporabi podobo (cum flueret lutulentus, 1.4.11), ki spominja na Kalimahovo blatno reko iz Himne Apolonu (108-9). Motiv reke, znan tudi iz retorične tradicije, ${ }^{22}$ ponovno srečamo $v$ deseti satiri (37; 50-51; 62), ki prav tako obravnava Lucilijevo poezijo, obenem pa je v neprestanem dialogu s Kalimahovimi verzi. Zgodba o Kvirinu je odgovor na besede namišljenega sogovornika, ki hvali Lucilijevo prepletanje grških in latinskih besed (20-21) in v podkrepitev svoje trditve navede primerjavo $\mathrm{z}$ mešanjem različnih vrst vina (24). Ruth Scodel je opozorila na paralele s tri-

19 Prim. Prop. 3.3.1.

20 Prim. Freudenburg, Walking Muse, 107.

21 Prim. prav tam, 158-62.

22 Scodel, "Horace, Lucilius, and Callimachean Polemic«, 206 ss. Prim. Freudenburg, Walking Muse, 106. 
najstim jambom, v katerem se Kalimah zagovarja pred kritiki, ki mu očitajo mešanje dialektov (11-21), in utemeljuje pisanje $\mathrm{v}$ različnih zvrsteh (polyeideia) (30-34). Tudi tu se pojavi prispodoba $\mathrm{z}$ mešanjem vina (19-21). ${ }^{23}$ Lucilijev občudovalec resda govori o dveh jezikih, Kalimah pa o različnih narečjih, a podobnosti so očitne. In medtem ko Kalimah zagovarja mešanje zvrsti, Horacij temu nasprotuje, saj lahko v določeni zvrsti le en pesnik doseže pravo kvaliteto (40-49).

Že Fraenkel je opazil, da Kvirinova izjava pravzaprav ni ustrezen odziv na pohvalo Lucilija, saj pri Luciliju sploh ne gre za pisanje grških verzov. Tema satire je v prav tolikšni meri Horacijeva lastna poezija. ${ }^{24}$ Ta v marsičem ustreza kalimahejskim idealom. Versiculi, ${ }^{25}$ o katerih govori Kvirin, se skladajo $\mathrm{z}$ vsebino naslednjih dveh verzov:

turgidus Alpinus ${ }^{26}$ iugulat dum Memnona dumque

diffingit Rheni luteum caput, haec ego ludo, (36-37)

medtem ko nabuhli Alpin kolje Memnona in preoblikuje rumenkasti izvir Rena, se jaz igram s temle (sc. s to poezijo),

Čeprav je Horacij nasprotoval 'opičjim' posnemovalcem Kalva in Katula (1819), ki neutemeljeno in brez prave mere občudujejo Lucilija, zdaj samega sebe predstavi z oznakami, značilnimi za neoterike (uersiculos, ludo). In če lahko v Kvirinovem svarilu prepoznamo odmev Kalimahovega jamba, sta navedena verza morda odgovor na Apolonovo zapoved. Pričakovali bi, da bo Kvirin podpiral vélike, epske teme, ${ }^{27}$ a se zgodi nasprotno: epika je zarisana v popolnoma kalimahejskem duhu (turgidus - $\pi$ axúc; ${ }^{28}$ luteum - lutulentus (1.4.11; 1.10.50) -

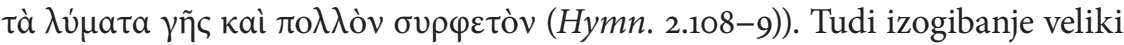
publiki (38-39) je značilno za kalimahejsko poetiko. A le par verzov zatem Horacij pohvali epskega in tragiškega pisca Varija Rufa (43-44). Podobna približevanja kalimahejstvu in odmiki od njega zaznamujejo vso satiro; omenimo le poudarjanje odlik, ki naj bi jih imeli pisci stare komedije, in zavzemanje za izpiljeno, z velikim trudom napisano poezijo v prvem delu pesmi.

Kalimahov Apolon v Horacijevem Kvirinu zaživi na novo; ne gre le za shematično prestavitev v nov, rimski ambient, temveč za preplet številnih raznolikih tradicij, ki si včasih med seboj izrazito nasprotujejo. Še več, satira osvetli napetosti znotraj ene same, na videz monolitne smeri.

23 Fraenkel, Horace, 130.

24 Zetzel, „Dreaming about Quirinus«, 44-45, opozarja, da Horacij z istim izrazom označi svoj 'prevod' Kalimahovega Epigrama 31 Pf. v Sat. 1.2.109.

25 Identifikacijo Alpina, ki naj bi bil po mnenju sholiastov neoterik Furij Bibakul, tu puščamo ob strani.

26 Scodel, »Horace, Lucilius, and Callimachean Polemic«, 202.

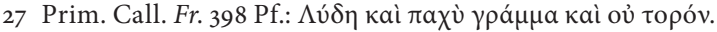

28 Prim. Doblhofer, »Horaz und Augustus«, 1937; Harrison, »Town and Country«, pass. 


\section{SATIRA 2.6: PROŠNJA MERKURJU}

Satira 2.6 sodi med tista Horacijeva dela, ki so jim interpreti njegove poezije posvečali največ pozornosti. $\mathrm{V}$ pesmi, ki se konča z znamenito adaptacijo ezopske zgodbe o mestni in podeželski miši, se namreč prvič pojavijo nasprotja, značilna za Horacijevo poznejšo poezijo: mesto in podeželje, javno in zasebno, stoiška in epikurejska drža, spokojno življenje na sabinskem posestvu in velemestni utrip Rima, kontemplacija in aktivno udejstvovanje, individuum in svet ... ${ }^{29}$ Verzi naj bi poleg Horacijeve življenjske filozofije razkrivali tudi odnos do Mecenata, ki je pesnika nedolgo pred nastankom satire obdaril s posestvom na Sabinskem. ${ }^{30}$

Prvi stihi prinašajo molitev $\mathrm{k}$ bogu Merkurju (Maia nate; 5). Horacijevo navdušenje nad prejetim podeželskim bivališčem se prelije $\mathrm{v}$ prošnjo:

hac prece te oro:

pingue pecus domino facias et cetera praeter

ingenium, utque soles, custos mihi maximus adsis. (13-15)

tako te prosim: nakloni gospodarju tolsto drobnico in vse ostalo, le zamaščenega duha ne; in - kakor vselej - bdi nad menoj kot najboljši varuh.

Nekoliko presenetljivo je, da je bog, ki naj bi Horaciju pripomogel k skromnosti in zadovoljstvu s tem, kar ima, ravno Merkur, ${ }^{31}$ toda ta je kot iznajditelj lire tudi zaščitnik pesnikov in ima za Horacija poseben pomen..$^{32}$ Morda je izbira boga tudi odraz Horacijeve samoironije. Namesto Kalimahove 'Muze' in Vergilijeve 'pesmi' stoji ingenium, ki ne sme biti pingue. ${ }^{33}$ Že Rudd je poudaril, da se prehrana podeželske miši ne razlikuje veliko od tega, kar jé Horacij, ${ }^{34}$ očitna in pogosto opažena pa je tudi zveza med navedeno prošnjo in zaključkom:

"... 'me silva cavosque

tutus ab insidiis tenui solabitur ervo.' (116-17)

»'mene bosta gozd in luknja, varna pred pastmi, potešila $\mathrm{z}$ drobnim grahom.'«

Tenue eruum spada tako $\mathrm{k}$ idealiziranemu preprostemu življenjskemu slogu kot v repertoar kalimahejske poetike. Opisi vsakdanjih dogodkov, opravil in

29 Prim. Muecke, Horace, 193-95.

30 Prim. Knorr, Verborgene Kunst, 209, op. 212.

31 Prim. Muecke, Horace, ad loc.

32 Prim. Horacijevo opredelitev satir v nadaljevanju (17): saturis musaque pedestri, in Kalimahovo

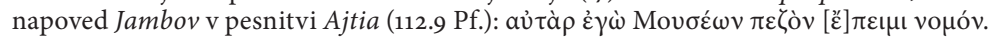

33 Rudd, Satires of Horace, 246.

34 Prim. Cody, Horace and Callimachean Aesthetics, 103-8 (o Sat. 2.6) in pass.; Mette, "Genus tenue und mensa tenuis«, pass. 
reči so hkrati metafore za pesniški stil..$^{35}$ Etika in estetika se v satirah nenehno prepletata; tudi v pesmih, ki na prvi pogled ne delujejo kot 'programske', najdemo številne aluzije na Kalimaha. Moralno sporočilo se ob tem ne izgubi, saj podobe istočasno učinkujejo na več nivojih. Horacijeve satire niso nič manj sofisticirane od njegovih od. ${ }^{36}$

\section{ODA 4.15: NAPOSLED HORACIJEV APOLON}

V zadnji odi se slednjič v vlogi svarilca pojavi Apolon:

Phoebus volentem proelia me loqui

victas et urbis increpuit lyra,

ne parva Tyrrhenum per aequor vela darem. $(1-4)$

Ko sem hotel peti o bitkah in premaganih mestih, je Fojb udaril po liri, naj se ne podajam na Tirensko morje $\mathrm{z}$ majhnimi jadri.

Izmed vseh obravnavanih odlomkov so ti verzi najbliže Kalimahovemu opisu srečanja z Apolonom, nespregledljive pa so tudi paralele z Vergilijevo šesto eklogo in aluzije na Propercija.

Kalimahovega mladeniča Apolon ne zaustavi, potem ko je ta že začel pisati neustrezne verze, zato ni potrebe, da bi bilo božje posredovanje agresivne narave; dovolj je, da bog mladega pesnika s pisalno deščico na kolenih le nagovori (عĩ $\varepsilon v)$. Vergilijev Titir pa je že zašel v zablodo, saj ga Apolon zaloti sredi dela (canerem), med petjem o kraljih in bitkah. Opredelitev zvrsti, ki je pustila pečat na številnih poznejših recusationes, je Vergilijeva iznajdba: reges et proelia, kralje in bitke, Vergilij najbrž vpelje pod vplivom kraljev in herojev, o katerih je na začetku Prologa govoril Kalimah. ${ }^{37}$

Apolonov pristop je tako upravičeno bolj ognjevit: aurem uellit et admonuit. Bržkone je na ta opis vplival Apolonov odnos do Ftonosa, poosebljene zavisti, iz zaključka Kalimahove druge himne (107), ki je poleg Prologa k pesnitvi Ajtia najpomembnejša podlaga za kalimahejsko poetiko: tòv $\Phi \theta$ óvov

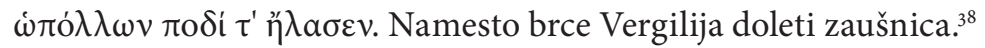

35 Freudenburg, Walking Muse, 185 ss. in pass.

$36 \mathrm{~V}$ tretjem verzu stoji beseda $\beta a \sigma \iota \lambda[\eta$, v petem pa п̆ $\rho \omega a \varsigma$. Prim. Cameron, Callimachus and His Critics, 457 ss.

37 Če je bil zgled za Apolonovo ravnanje v šesti eklogi res verz iz Himne Apolonu, ki prinaša odziv

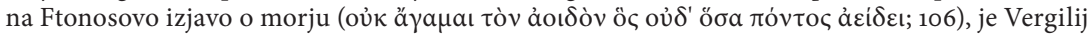

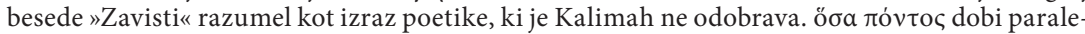
lo v reges et proelia, v epiki, ki jo Vergilijev Apolon zavrača. To govori proti Williamsovi priljubljeni hipotezi, da je morje za Kalimaha pozitivna podoba, saj simbolizira Homerja (Williams, Callimachus, 87 ss.).

38 Prim. Hor. Sat. 2.6.5: pingue pecus. Na paralelo opozarja Helena Dettmer, Horace, 284. 
Apolonovo navodilo je v eklogi preoblikovano tako, da ustreza bukolični zvrsti: namesto $\theta$ v́oৎ $\pi$ áxı

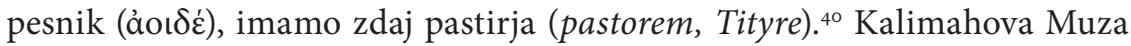
(Moṽ $\alpha v \lambda \varepsilon \pi \tau \alpha \lambda \varepsilon \dot{\eta} v)$ postane deductum carmen in najde odmev v osmem verzu, kjer Vergilij omenja kmečko Muzo, agrestem Musam:

agrestem tenui meditabor harundine Musam

jaz pa na tanko trstiko ubiral bom kmečke napeve ${ }^{41}$

Horacijev pesnik v C. 4.15 še ne 'poje', a si tega želi (uolentem). V tem bolj spominja na Kalimahovega mladeniča, vendar opredelitev vsebine zaželenih verzov kaže na očiten Vergilijev vpliv: proelia verjetno izhajajo iz Ecl. 6, namesto reges pa pri Horaciju stojijo uictas urbes,${ }^{42}$ posledice vojn ${ }^{43} \mathrm{ki}$ jih povzročajo kralji in tudi njihov naslednik, 'novi Romul'. ${ }^{44}$ Apolon bojevito udari po liri (increpuit lyra) ${ }^{45}$ in tako Horacija hkrati zaustavi in inspirira za drugačno pesnjenje. ${ }^{46}$ Tyrrhenum aequor, na katero se Horacij s svojimi premajhnimi jadri ne sme podati, je prav tisto morje, po katerem po pričevanju Junone na začetku Eneide plujejo Trojanci:47

gens inimica mihi Tyrrhenum nauigat aequor

Ilium in Italiam portans uictosque penatis: $(1.67-68)$

glej, sovražen mi rod zdaj jadra po morju Tirenskem

Ilij noseč in pobite penate $\mathrm{v}$ deželo Italsko. ${ }^{48}$

Plovbo v prenesenem pomenu, ki spominja na Horacijev zaključek prve strofe, srečamo v pesnitvi Georgika:

Maecenas, pelagoque uolans da uela patenti. (2.41)

jadra široko razpni in polêti z menoj na odprto. ${ }^{49}$

\footnotetext{
39 Prim. Lyne, Horace, 32-33.

40 Prev. Marko Marinčič.

41 Prim. 4.15: miseras ... urbis (20) in Troiam (31) kot simbol 'nesrečnih' in 'premaganih' mest.

42 Prim. Hor. AP 73: res gestae regumque ducumque et tristia bella. Zadnja sintagma (tristia bella) se pojavi tudi v sedmem verzu šeste ekloge.

43 Prim. Putnam, Artifices of Eternity, 269.

44 Morda gre tudi tu poleg Vergilijevega vpliva za aluzijo na Kalimahovo Himno Apolonu. Podobno vprašanje si zastavi Syndikus, Die Lyrik des Horaz, 422, op. 12. O liri govorita tudi Propercij (3.3.14): sic ait aurata nixus ad antra lyra, in Ovidij (Ars am. 494): mouit inauratae pollice fila lyrae.

45 Johnson, Symposion of Praise, 209-10 in 276, op. 60.

46 Putnam, Artifices of Eternity, 269.

47 Prev. Fran Bradač.

48 Prev. Marko Marinčič.

49 Prim. Steiner, Crown of Song, 73-75; Nünlist, Poetologische Bildersprache in der frühgriechischen Dichtung, 265-76.
} 
Horacij se s prispodobo morja in plovbe nasloni na dolgo tradicijo, saj že pri Pindarju pot po morju simbolizira pesnjenje..$^{50}$ Homerja zelo pogosto primerjajo z oceanom..$^{51}$ Horacij v prvi kitici preplete aluzije na Kalimahov Prolog in na zaključek Himne Apolonu, kjer srečamo morje, ki morda predstavlja Homerja. Da gre pri Horaciju za namig na Eneido, je še bolj jasno iz nadaljevanja pesmi, kjer je paralel k Vergiliju zelo veliko: trofeje na vratih svetišča (68; prim. Aen. 8.721-22), zaprtje Janovega templja (8-9; prim. Aen. 1.293-94), seznam podjarmljenih ljudstev (21-24; prim. Aen. 8.722-28). Zadnja dva verza ode, ki napovedujeta petje o Troji, Anhizu in Venerinem rodu, obljubljata pesem, enakovredno Eneidi.

Obilju aluzij na Vergilija se pridružuje tudi nedvomen pečat Propercijeve tretje knjige. Tretja elegija prinaša pesniško iniciacijo: govorec pripoveduje, kako je v sanjah (!) s svojimi majhnimi usti zajel navdih iz velikega izvira, iz katerega je nekoč pil Enij, in pel o slavni rimski preteklosti:

cum me Castalia speculans ex arbore Phoebus

sic ait aurata nixus ad antra lyra:

"quid tibi cum tali, demens, ${ }^{52}$ est flumine? quis te

carminis heroi tangere iussit opus?« (13-16)

Febus tedaj me uzre iz gaja ob kastalijskem viru, tam ob votlini stoječ z zlato mi liro $\mathrm{v}$ rokah, pravi tako mi: »Bedak, kaj iščeš v mogočni tej reki?

Kdo velél je, povej, peti junaški ti ep?«53

Pozicija poudarjenih besed Phoebus in lyra na koncu zaporednih verzov odmeva $\mathrm{v}$ postavitvi istih dveh izrazov na začetku prvega in na koncu drugega verza v Horacijevi pesmi. ${ }^{54}$ Rečna metaforika spominja na Kalimahovo Himno Apolonu, ${ }^{55} \mathrm{v}$ glagolu iussit pa prepoznamo Vergilijeve besede iz šeste

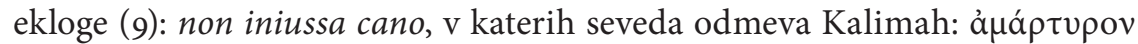
oủ $\delta \dot{\varepsilon} v$ ảeí $\delta \omega(F r .612$ Pf.).

Metaforo plovbe prinašajo verzi v nadaljevanju:

non est ingenii cumba gravanda tui.

alter remus aquas alter tibi radat harenas,

tutus eris: medio maxima turba marist. (22-24)

50 Prim. Quint. Inst. Orat. 10.1.46.

$51 \mathrm{~V}$ besedi demens se najbrž skriva tudi namig na pesniško norost, prim. Prop. 4.1.71 (Horus): Quo ruis imprudens, uage, dicere fata, Properti?; 4.1.133-34: tum tibi pauca suo de carmine dictat Apollo / et uetat insano uerba tonare foro; Hor. Sat. 1.10.34: in siluam non ligna feras insanius ac si; Ovid. Ars am. 508: non sanus poeta.

52 Putnam, Artifices of Eternity, 267.

53 Prim. Kambylis, Die Dichterweihe und ihre Symbolik, 147; Harrison, »Primal Voyage and Ocean of Epos«, 11.

54 Prev. Jože Mlinarič.

55 Prev. Jože Mlinarič. 
Pesniški ladji ne smeš dati pretežkih bremen!

$\mathrm{Z}$ enim mi veslom vodó, a $\mathrm{z}$ drugim pa pesek mi gladi.

Varno plul boš tedaj! Sredi morja je vihar! ${ }^{56}$

Še tesnejša povezava s C. 4.15 je v deveti elegiji, naslovljeni na Mecenata:

quid me scribendi tam vastum mittis in aequor?

non sunt apta meae grandia vela rati. (3-4)

kaj me s pesmijo, čuj, pošiljaš na morje visoko?

Ladjica moja lahkó majhna le jadra ima! ${ }^{57}$

(Dobesedno: Velika jadra niso primerna za mojo ladjo.) $)^{58}$

Besednih paralel zopet ni mogoče spregledati: aequor tako pri Horaciju kot pri Properciju stoji na koncu tretjega verza, v naslednjem verzu pa imamo pri obeh pesnikih izraz uela. Tudi nasprotje med velikim in majhnim je podobno, le v drobnih razlikah razberemo Horacijevo izvirnost: morje, pri katerem Propercij poudari obsežnost (uastum aequor), pri Horaciju ne dobi posebne količinske oznake, ampak je njegova 'epskost' nakazana z namigom na Vergilija (Tyrrhenum per aequor); Horacijeva jadra so majhna (parua uela), pri Properciju pa so - nasprotno - velika jadra ( grandia uela) neprimerna za njegov čoln.99

Po Horacijevem tako rekoč tradicionalnem uvodu bralec, vajen podobnih recusationes, ki v verzih razbere tako sledi Vergilijeve šeste ekloge kot Propercijeve tretje in devete elegije, pričakuje nadaljevanje v predvidljivi maniri: umik v bukolično ali ljubezensko poezijo in le indirekten enkomij vladarju. A Horacij še v isti kitici napove veliko presenečenje (4): tua, Caesar, aetas. ${ }^{60}$ Apolonove besede se nadaljujejo z očitnim panegirikom, Avgust in njegova doba sta v središču do zadnjega verza. Brez kakršnega koli izmikanja in lažne skromnosti, brez vseh opravičil zapoje Horacij odo, ki se v zadnjih dveh strofah prelije v obet nove Eneide. ${ }^{61} \mathrm{Ne}$ gre le za novo napetost med vojno in mirom, ${ }^{62}$ na katero se Horacij iz povsem političnih razlogov odzove s hvalnico slednjemu, ${ }^{63}$ in tudi ne za običajno vključevanje epskih značilnosti v lirsko zvrst, ampak za transformacijo brezosebne epike in intimne elegije v novo, javno liriko, ki spominja na starodavno himniko. ${ }^{64}$

56 Prim. Prop. 3.9.35-36: non ego uelifera tumidum mare findo carina: / tota sub exiguo flumine nostra morast.

57 Prim. Ov. Ars am. 3.26 o ljubezenski veščini: Conueniunt cumbae vela minora meae; Ov. Trist. 2.1.547-48: ne tamen omne meum credas opus esse remissum, / saepe dedi nostrae grandia vela rati.

58 Prim. Syndikus, Die Lyrik des Horaz, 423.

59 Predzadnja kitica se začne s poudarjenim zaimkom nos(que), stavek pa se konča z zadnjim verzom pesmi, s prav tako poudarjenim glagolom canemus. Prim. Harrison, "Primal Voyage and Ocean of Epos«, 11-12.

60 Prim. Wimmel, Kallimachus in Rom, 136.

61 Prim. npr. Fraenkel, Horace, 449-53; Lowrie, Horace's Narrative Odes, 345.

62 Putnam, Artifices of Eternity, 306 in pass.

63 Prim. npr. Fraenkel, Horace, 449-53; Lowrie, Horace's Narrative Odes, 345.

64 Putnam, Artifices of Eternity, 306 in pass. 
Horacijev Apolon je torej tudi v zadnji pesmi, ko na svoj zgled, podobo Apolona pri Kalimahu, spominja bolj kot kadar koli doslej, predvsem dokaz Horacijeve velike izvirnosti.

\section{BIBLIOGRAFIJA}

Brink, Charles O. Horace on Poetry. Epistles Book II. The Letters to Augustus and Florus. Cambridge: Cambridge University Press, 1982.

Cameron, Alan. Callimachus and His Critics. Princeton: Princeton University Press, 1995. Cavarzere, Alberto. Orazio. Il Libro degli Epodi. Venice: Marsilio, 1992.

Cody, John V. Horace and Callimachean Aesthetics. Collection Latomus 147. Brussels: Latomus, 1976.

Davis, Gregson. Polyhymnia. The Rhetoric of Horatian Lyric Discourse. Berkeley / Los Angeles: University of California Press, 1991.

Dettmer, Helena. Horace. A Study in Structure. Altertumswissenschaftliche Texte und Studien 12. New York: Olms-Weidman, 1983.

Doblhofer, Ernst. »Horaz und Augustus.« ANRW II 31.3 (1981): 1922-86.

Fraenkel, Eduard. Horace. Oxford: Clarendon Press, 1957.

Harrison, Stephen J. "The Literary Form of Horace's Odes.« V: Horace. L'oeuvre et les imitations. Un siècle d'interprétation, ur. W. Ludwig, 131-62. Entretiens sur l'antiquité classique 39. Genève: Fondation Hardt, 1993.

—__. „Some Generic Problems in Horace's Epodes. Or, On (Not) Being Archilochus.» V: Iambic Ideas. Essays on a Poetic Tradition from Archaic Greece to the Late Roman Empire, ur. A. Cavarzere, A. Aloni in A. Barchiesi, 165-86. Greek Studies: Interdisciplinary Approaches. Lanham, MD: Rowman \& Littlefield, 2001.

___ . "Town and Country." V: The Cambridge Companion to Horace, ur. S. Harrison, 235-47. Cambridge: Cambridge University Press, 2007.

—_. $» T$ The Primal Voyage and the Ocean of Epos. Two Aspects of Metapoetic Imagery in Catullus, Virgil and Horace.« Dictynna 4 (2007). http://dictynna.revue.univ-lille3. fr/DictynnaNumero4.html.

Ingallina, Salvatore. »Non elaboratum ad pedem (Hor. epod. 14, 12).« GIF 27 (1975): 201-9. Johnson, Timothy. Symposion of Praise. Horace Returns to Lyric in Odes IV. Wisconsin Studies in Classics. Madison, WI: University of Wisconsin Press, 2004.

Kambylis, Athanasios. Die Dichterweihe und ihre Symbolik. Untersuchungen zu Hesiodos, Kallimachos, Properz und Ennius. Bibl. d. Klass. Altertumswiss. N.F. Heidelberg: Carl Winter, 1965.

Kiessling, Adolf in Richard Heinze. Quintus Horatius Flaccus. Oden und Epoden. Berlin: Weidmann, $1984^{14}$.

Knorr, Ortwin. Verborgene Kunst. Argumentationsstruktur und Buchaufbau in den Satiren des Horaz. Hildesheim: Olms-Weidmann, 2004.

Lefèvre, Eckard. Horaz. Dichter im augusteischen Rom. München: C. H. Beck, 1993.

Lowrie, Michèle. Horace's Narrative Odes. Oxford: Clarendon Press, 1997.

Lyne, R. O. A. M. Horace. Behind the public poetry. New Haven / London: Yale University Press, 1995.

Mette, Hans J. "Genus tenue und mensa tenuis bei Horaz." MH 18 (1961): 136-39.

Muecke, Frances. Horace. Satires II. Warminster: Aris \& Phillips, 1993. 
Nisbet, Robin G. M. in Margaret Hubbard. A Commentary on Horace. Odes. Book 1. Oxford: Clarendon Press, 1970.

Nünlist, René. Poetologische Bildersprache in der frühgriechischen Dichtung. Stuttgart: Teubner, 1998.

Putnam, Michael C. J. Artifices of Eternity. Horace's Fourth Book of Odes. Ithaca, N.Y. I London: Cornell University Press, 1986.

Rudd, Niall. The Satires of Horace. Cambridge: Cambridge University Press, 1966.

Scodel, Ruth. »Horace, Lucilius, and Callimachean Polemic.« HSPh 91 (1987): 199-215.

Steiner, Deborah. The Crown of Song. Metaphor in Pindar. London: Duckworth, 1986.

Syndikus, Hans P. Die Lyrik des Horaz. Eine Interpretation der Oden. Bd. II: Drittes und viertes Buch. Impulse der Forschung 7. Darmstadt: Wissenschaftliche Buchgesellschaft, 1973.

Watson, Lindsay C. »Epode 14: Horace's Carmen Inconditum?« V: Iambic Ideas. Essays on a Poetic Tradition from Archaic Greece to the Late Roman Empire, ur. A. Cavarzere, A. Aloni in A. Barchiesi, 187-204. Greek Studies: Interdisciplinary Approaches. Lanham, MD: Rowman \& Littlefield, 2001.

- A Commentary on Horace's Epodes. Oxford: Oxford University Press, 2003.

White, Peter. Promised Verse. Poets in the Society of Augustan Rome. Cambridge: Harvard University Press, 1993.

Wili, Walter. Horaz und die augusteische Kultur. Basel: Benno Schwabe \& Co., 1948.

Williams, Frederick. Callimachus. Hymn to Apollo. A Commentary. Oxford: Oxford University Press, 1978.

Wimmel, Walter. Kallimachos in Rom. Die Nachfolge seines apologetischen Dichtens in der Augusteerzeit. Wiesbaden: Hermes Einzelschriften 16, 1960.

Zetzel, James E. G. »Dreaming about Quirinus. Horace's Satires and the Development of Augustan Poetry.« V: Traditions and Contexts in the Poetry of Horace, ur. Anthony J. Woodman in Denis C. Feeney, 38-52. Cambridge: Cambridge University Press, 2002.

\section{PHOEBUS VOLENTEM PROELIA ME LOQUI: THE APOLLO OF CALLIMACHUS IN HORACE}

\section{Summary}

The Augustan poets often modelled their recusationes on Callimachus' portrayal of Apollo in the Aetia Prologue. The paper discusses parallel passages in Horace's oeuvre, illustrating some typical characteristics of Horace's poetry and of his attitude to his poetic models.

After a brief introduction, the paper first touches on three poems by Horace where the role of Callimachus' Apollo is taken over by another deity: the Muse in C. 1.6.10-12, Venus in C. 1.19.9-12, and a deus (presumably Cupid) in Epod. 14.6-8. The three examples display similarities to, rather than identity with, the Callimachean situation: instead of supplying a direct quote, Horace merely reports the words of a 'higher power' which allegedly prevented him 
from writing what he wanted or what was expected of him. In the two Odes Horace thus refuses to compose an epic, while Epode 14 is not a typical recusatio: Horace's polished iambics paradoxically profess his inability to compose iambic poetry, and his preference for erotic lyric poetry.

The next section focuses on Satire 1.10.31-35, which portrays the Roman god Quirinus warning the young poet in a dream that writing Greek verse is pointless. An analysis of this complex programmatic satire reveals continual departures from, and approximations to, Callimachean poetic, as Horace interweaves several, at times clearly irreconcilable, traditions. Indeed, Callimachean poetic itself is not unequivocal or monolithic but contains many tensions.

The short fourth section discusses Horace's prayer to Mercury in Satire 2.6.13-15. Although superficially lacking a 'programmatic' dimension, the satire in fact contains several allusions to Callimachus. It serves to show that Horace's images function at several levels at once, and that his satires closely interweave ethics with aesthetics.

The final and longest section focuses on Horace's last poem, C. 4.15. In the first strophe, Horace is finally given a warning by Apollo himself. Of all the passages discussed, this one comes closest to the description of Callimachus' Apollo in the Aetia Prologue. Besides a detailed analysis of the similarities and contrasts between the two poets' portrayals of Apollo, the fifth section includes a comparison with Vergil's sixth Eclogue and Propertius' third book of elegies, which undoubtedly served as Horace's models as well. A prominent function is given to the metaphor of seafaring, which is linked by all three Roman poets to the composition of epic poetry. The paper, moreover, underlines the surprising continuation of Ode 4.15: rather than retreat into bucolic or erotic poetry, as might be expected, Horace openly launches into an ode heralding a new Aeneid and evoking ancient hymnic poetry. Even in the final poem, Horace's Apollo thus testifies to Horace's originality in reworking his models. 